\title{
Mandatory Nicotine Cessation for Elective Orthopedic Hip Procedures Results in Reduction in Postoperative Nicotine Use
}

Brian M. Rao ${ }^{1}$, Daniel D. Moylan ${ }^{1}$, Kyle R. Sochacki ${ }^{2,}{ }^{3}$, Robert C. Kollmorgen ${ }^{4}$, Lakhvir Atwal ${ }^{1}$, Thomas J. Ellis 5

1. Orthopedics, Orthopedic One, Dublin, USA 2. Orthopedic Surgery, Orthopedic One, Columbus, USA 3. Orthopedics and Sports Medicine, Houston Methodist Hospital, Houston, USA 4. Hip Preservation and Sports Medicine, University of California San Francisco, Fresno, USA 5. Orthopedic Surgery, Orthopedic One, Dublin, USA

Corresponding author: Brian M. Rao, brao7ptl@gmail.com

\section{Abstract \\ Purpose}

To determine the efficacy of mandatory preoperative nicotine cessation on postoperative nicotine use, and to identify independent predictors of nicotine use relapse in subjects undergoing hip preservation surgery or total hip arthroplasty by a single fellowship-trained orthopedic surgeon.

\section{Methods}

Consecutive subjects that underwent hip surgery from November 2014 to December 2017 were reviewed. Subjects who self-reported nicotine use, quit prior to surgery, and completed a minimum one-year follow-up were included. Multiple linear regression models were constructed to determine the effect of independent variables on nicotine use relapse following surgery.

\section{Results}

Sixty subjects were included in the study (mean follow-up 35.1 months (17-57 months), mean age 44.9 years (20-82 years), and 23 (38.3\%) males). Twenty-eight subjects (46.7\%) remained nicotine-free at final followup. The mean number of cigarettes per day decreased from 13.4 preoperatively to 8.4 postoperatively in the subjects who relapsed $(\mathrm{P}=0.002)$. The mean time to return to nicotine postoperatively was 2.4 months. The number of preoperative cigarettes per day was the only independent predictor of tobacco use relapse $(\mathrm{P}=0.005)$.

\section{Conclusion}

Mandatory preoperative nicotine cessation prior to elective hip surgery demonstrates a $46.7 \%$ nicotine-free survivorship at final follow-up with the number of preoperative cigarettes per day found to be the only independent predictor of nicotine use relapse.

Review began 09/24/2020 Review ended 12/17/2020 Published 12/18/2020

\section{(c) Copyright 2020}

Rao et al. This is an open access article distributed under the terms of the Creative Commons Attribution License CC-BY 4.0., which permits unrestricted use, distribution, and reproduction in any medium, provided the original author and source are credited.

\section{Level of evidence}

The level of evidence of this research study is Level III since it is a non-experimental study with a cohort of patients.

Categories: Orthopedics, Pulmonology

Keywords: hip preservation, hip replacement, primary arthroplasty, epidemiology, orthopedic, surgery, total hip arthroplasty, smoking, smoking cessation, nicotine

\section{Introduction}

Tobacco use in the United States remains problematic, despite a long-term decline [1]. It remains the leading cause of preventable death in the U.S. with cigarette smoking responsible for more than 480,000 deaths each year according to the Centers for Disease Control and Prevention (CDC) [2]. Compared to non-smokers, smokers are more likely to develop cancers, cardiovascular disease, pulmonary disease, impaired immune function, and reduced life expectancy [3-5].

Furthermore, smokers are at a higher risk for surgical and postoperative complications [6-11]. Alverdy and Prachand reported that smoking nearly doubles the risk of surgical site infections (SSI) [12]. In an analysis of a large national database, Duchman et al. found that smokers had an increased risk of wound complications and deep infections [13]. The Lower Extremity Assessment Project (LEAP) also found that in open fractures, smokers were twice as likely to develop an infection and 3.7 times more likely to develop osteomyelitis [14]. Evidence suggests that smoking cessation as early as four weeks preoperatively significantly reduces the 
likelihood of complications, although a timeline for the impact of cessation is lacking [15-19].

The effectiveness of nicotine cessation interventions is not well established. In general, smoking cessation methods have had mixed rates of success. In a meta-analysis, recidivism rates at six months ranged from $69.5 \%$ to $88.2 \%$ for all cessation methods used and $95 \%$ to $97 \%$ with self-quitting methods [20]. Ucar et al. reported the recidivism rate of 422 patients using pharmacologic therapies to quit smoking was $65 \%$ at 3 months [21].

The preoperative time point has been consistently cited as a "teachable moment" that offers a uniquely effective opportunity for smoking cessation [22-24]. However, many patients quickly return to smoking. Carlson et al. report smoking recidivism rates following spinal surgery of $60 \%$ at three months postoperatively, $61 \%$ at six months postoperatively, and $68 \%$ at one year postoperatively [25]. In smaller studies and systemic analysis, $13-56.3 \%$ of patients have achieved long-term cessation at a minimum of one year postoperatively through following various preoperative interventions [23-25].

The effectiveness of nicotine cessation programs in patients undergoing elective hip procedures has not been adequately evaluated. The purpose of the study was to determine the efficacy of mandatory preoperative nicotine cessation on postoperative nicotine use and to identify the independent predictors of nicotine use relapse in subjects undergoing hip preservation surgery or total hip arthroplasty. The authors hypothesized that less than $50 \%$ of subjects would remain nicotine-free at final follow up and that there would be no independent predictors of nicotine use relapse.

\section{Materials And Methods}

Institutional Review Board (IRB) approval was obtained for this retrospective case series. Consecutive subjects who underwent hip preservation surgery or total hip arthroplasty by a single fellowship-trained orthopedic surgeon from September 2014 to December 2017 were reviewed. Subjects aged $>18$ years old who self-reported nicotine use, quit using nicotine prior to surgery, and completed a minimum one-year followup were included in the study. Pediatric subjects and non-native English speakers who could not complete informed consent were excluded (Figure 1).

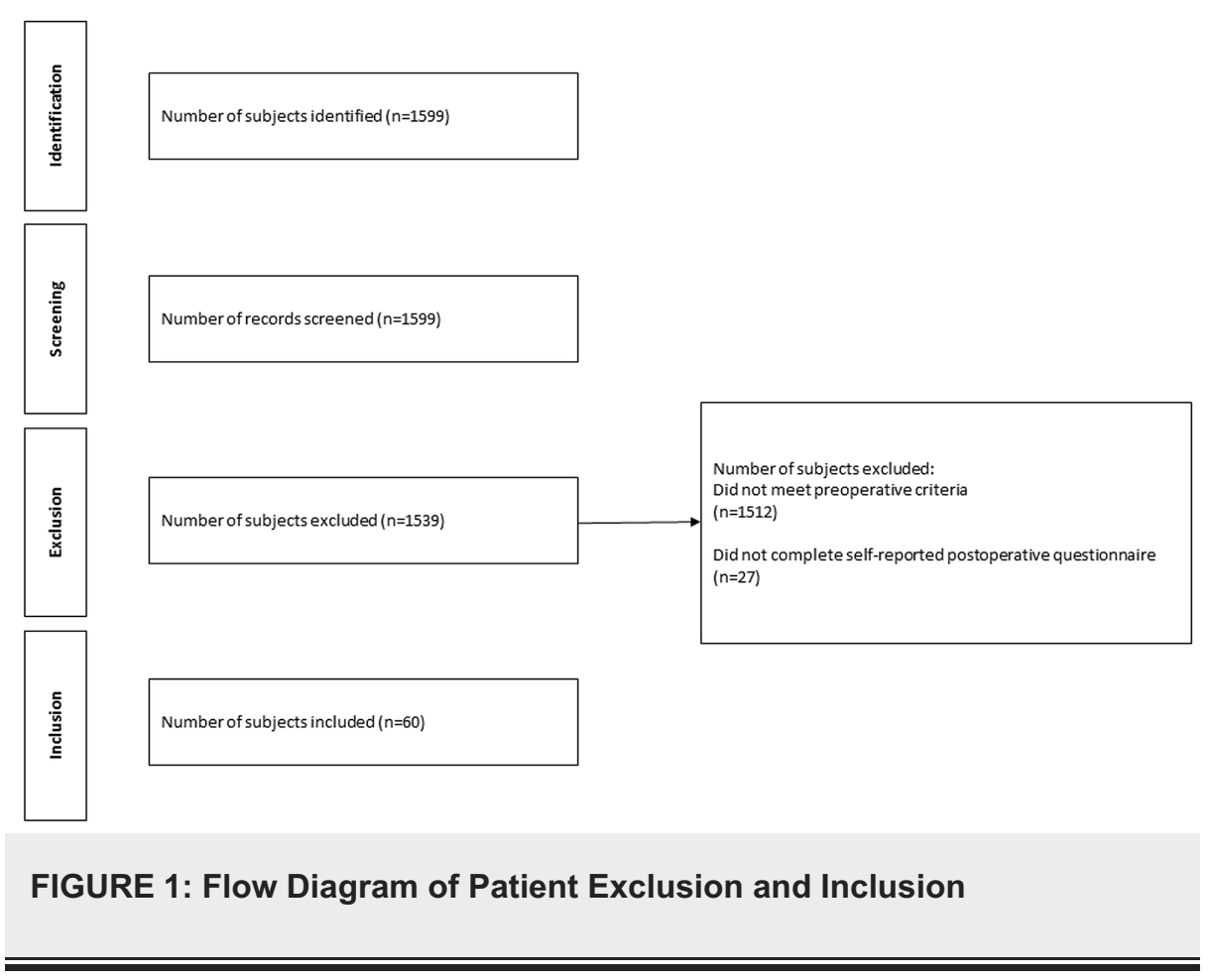

Self-reported nicotine use was assessed at all patient visits, including their immediate preoperative appointment. Subjects were routinely counseled on the risks associated with nicotine use from smoking, vaping, or chewing tobacco. All subjects undergoing surgery who reported nicotine use were required to quit nicotine use within four weeks of their surgery. This was confirmed by negative serum nicotine/cotinine levels. All subjects were asked to complete a nicotine use survey at their most recent followup (Appendices). Subjects who reported nicotine use at any time point after surgery were considered to have relapsed and considered nicotine users.

Subject demographics including age, sex, body mass index (BMI), and surgical procedure was recorded. Nicotine users and nicotine-free subjects were compared. Data analysis was performed using Microsoft 


\section{Cureus}

Excel for Mac 2018, version 16.16.14 (Microsoft, Redmond, WA, USA). The significance of differences in means of continuous variables between two groups was determined using the Student's t-test. Categorical variables were compared using Fisher's exact test. Multiple linear regression models were constructed to determine the effect of independent variables (age, sex, BMI, number of years of prior tobacco use, and the number of preoperative cigarettes per day) on nicotine use relapse following surgery. Categorical variables were coded as dummy variables (i.e., for gender, zero-male, one-female). All P-values were reported, and a significance level of $\mathrm{P}<0.05$ was used.

\section{Results}

Sixty subjects were included in the study (Table 1 ). The mean postoperative follow-up was 35.1 (12-57) months. The mean age was 44.9 (20-82) years old, with 23 (38.3\%) males and 37 (61.7\%) females. Procedures performed included 33 total hip arthroplasties (55.0\%), 17 (28.3\%) hip arthroscopies, 3 (5.0\%) iliopsoas tenotomies, 2 (3.3\%) periacetabular osteotomies, and 5 (8.4\%) other hip preservation-related surgeries. The majority of subjects smoked cigarettes compared to other forms of nicotine preoperatively $(86.7 \%)$ and postoperatively (78.1\%) with most subjects (57.7\%) beginning regular nicotine use after the age of 18 (Table 2). Fifty-two (86.7\%) subjects quit using nicotine preoperatively unassisted.

\begin{tabular}{|c|c|c|c|}
\hline Demographic & All $(n=60)$ & Nicotine Users After Surgery $(n=32)$ & Nicotine-Free After Surgery $(n=28)$ \\
\hline Mean age (years) (range) & $44.9(20-82)$ & $47.7(21-80)$ & $41.6(20-82)$ \\
\hline \multicolumn{4}{|l|}{ Sex } \\
\hline Female & $37(61.7 \%)$ & $20(62.5 \%)$ & 17 (60.7\%) \\
\hline Male & $23(38.3 \%)$ & $12(37.5 \%)$ & 11 (39.3\%) \\
\hline Mean BMI $\left(\mathrm{kg} / \mathrm{m}^{2}\right)$ (range) & $29.6(18.2-42.1)$ & $30.3(18.2-42.1)$ & $28.7(19.6-41.6)$ \\
\hline \multicolumn{4}{|l|}{ Type of surgery } \\
\hline THA & 33 (55.0\%) & 17 (53.1\%) & $16(57.1 \%)$ \\
\hline Hip arthroscopy & $17(28.3 \%)$ & $9(28.1 \%)$ & $8(28.7 \%)$ \\
\hline lliopsoas tendon & $3(5.0 \%)$ & $3(9.4 \%)$ & - \\
\hline PAO & $2(3.3 \%)$ & - & $2(7.1 \%)$ \\
\hline Other & $5(8.4 \%)$ & $3(9.4 \%)$ & $2(7.1 \%)$ \\
\hline
\end{tabular}

\section{TABLE 1: Subject Demographics}

THA: total hip arthroplasty, PAO: periacetabular osteotomy, BMI: body mass index. 


\section{Cureus}

\begin{tabular}{|c|c|c|c|}
\hline Demographic & All $(n=60)$ & $\begin{array}{l}\text { Nicotine Users After Surgery } \\
(n=32)\end{array}$ & Nicotine-Free After Surgery $(n=28)$ \\
\hline \multicolumn{4}{|l|}{ Nicotine products used } \\
\hline Cigarettes & $\begin{array}{l}52 \\
(86.7 \%)\end{array}$ & $25(78.1 \%)$ & 27 (96.4\%) \\
\hline Chewing tobacco & $1(1.7 \%)$ & $1(3.1 \%)$ & - \\
\hline Cigars/pipes & $2(3.3 \%)$ & $1(3.1 \%)$ & $1(3.6 \%)$ \\
\hline Electronic cigarettes & $2(3.3 \%)$ & $2(6.3 \%)$ & - \\
\hline Vaporizers & $1(1.7 \%)$ & $1(3.1 \%)$ & - \\
\hline Other & $2(3.3 \%)$ & $2(6.3 \%)$ & - \\
\hline \multicolumn{4}{|l|}{ Age of regular nicotine use } \\
\hline 18 and under & $\begin{array}{l}22 \\
(42.3 \%)\end{array}$ & $10(37.0 \%)$ & $12(48.0 \%)$ \\
\hline 19 and older & $\begin{array}{l}30 \\
(57.7 \%)\end{array}$ & $17(63.0 \%)$ & $13(52.0 \%)$ \\
\hline Mean years of prior nicotine use (range) & $\begin{array}{l}23.5(1- \\
50)\end{array}$ & $23.9(1-45)$ & $23.5(3-50)$ \\
\hline Mean preoperative cigarettes per day (range) & $\begin{array}{l}12.9(1- \\
40)\end{array}$ & $13.4(2-40)$ & $12.3(1-30)$ \\
\hline $\begin{array}{l}\text { Mean postoperative cigarettes per day } \\
\text { (range) }\end{array}$ & $3.2(0-40)$ & $8.4(1-40)$ & 0 \\
\hline \multicolumn{4}{|l|}{ Nicotine cessation methods } \\
\hline "Cold Turkey" no assistance & $\begin{array}{l}52 \\
(86.7 \%)\end{array}$ & 27 (84.4\%) & $25(89.3 \%)$ \\
\hline Nicotine patches & $3(5.0 \%)$ & $2(6.3 \%)$ & $1(3.6 \%)$ \\
\hline Prescription & $2(3.3 \%)$ & - & $2(7.1 \%)$ \\
\hline Tapered down & $1(1.7 \%)$ & $1(3.1 \%)$ & - \\
\hline Hypnotism & $1(1.7 \%)$ & $1(3.1 \%)$ & - \\
\hline Zero vaporizers & $1(1.7 \%)$ & $1(3.1 \%)$ & - \\
\hline
\end{tabular}

TABLE 2: Nicotine Use History

Forty (66.7\%) subjects either quit nicotine entirely or used less than they did before their surgery. The mean number of cigarettes per day decreased from $13.4(2-40)$ preoperatively to $8.4(1-40)$ postoperatively in the subjects who relapsed $(\mathrm{P}=0.002$; Table 2$)$. There were no other significant differences $(\mathrm{P}>0.05)$ in subject demographics or tobacco use in the nicotine-free group compared to the nicotine users and postoperatively compared to preoperatively.

Twenty-eight subjects (46.7\%) were nicotine-free and 32 subjects (53.3\%) self-reported as nicotine users at final follow-up. The mean time to return to nicotine use was $2.4+2.7$ months postoperatively. In multivariate analysis (Table 3), only the number of preoperative cigarettes per day was an independent predictor of nicotine use relapse $(\mathrm{P}=0.005)$. No other subject-specific variables had any significant association with nicotine use relapse postoperatively. 


\section{Cureus}

\begin{tabular}{|c|c|c|}
\hline Variable & Regression Coefficient & P-value \\
\hline Age & -0.045 & 0.806 \\
\hline Sex & -0.587 & 0.813 \\
\hline Body mass index & 0.372 & 0.065 \\
\hline No. of years prior nicotine use & 0.005 & 0.979 \\
\hline No. of preoperative cigarettes per day & 0.447 & $0.005^{\star}$ \\
\hline
\end{tabular}

\section{Discussion}

It was determined that 28 subjects (46.7\%) remained nicotine-free at the final follow-up. For the patients who resumed smoking, the mean postoperative number of cigarettes per day significantly decreased compared to preoperatively. Additionally, the number of preoperative cigarettes per day was the only independent predictor of nicotine use relapse. This partially confirmed the authors' hypotheses.

Postoperative complications associated with nicotine use is a major preventable risk factor. Moller et al. reported numerous complications from smoking tobacco including impaired wound healing, cardiopulmonary complications [9,10], and the need for postoperative intensive care [26]. Smoking cessation four weeks prior to surgery has been shown to positively affect the outcomes of patients and reduce surgical complications [15-19].

Tobacco and nicotine cessation is challenging for an active smoker and often unsuccessful without assistance [26,27]. Prior studies investigating preoperative smoking cessation programs have demonstrated success rates ranging from $32 \%$ to $52 \%$ at final follow-up $[21,23-25,28]$ with nicotine supplementation found to be the most effective adjunct compared to perioperative education and behavioral therapy. This is similar to the present study in which $46.7 \%$ of subjects remained nicotine-free at final follow-up. However, the vast majority of subjects (86.7\%) were able to quit “cold turkey" without assistance in the present study.

Additionally, a previous study by Hart et al. demonstrated that greater than $60 \%$ of subjects were able to remain tobacco-free at three-year follow-up [28]. The increased tobacco-free survival compared to the present study is likely due to the inclusion of only subjects who were undergoing total knee and total hip arthroplasty while the current study also included less invasive procedures such as hip arthroscopy. Shi and Warner previously demonstrated that more invasive or major surgeries have a greater impact on preventing tobacco use relapse compared to outpatient surgeries such as hip arthroscopy [22].

Mandatory preoperative nicotine cessation also led to reduced nicotine consumption in those subjects who relapsed with the mean number of cigarettes per day decreasing from 13.4 (2-40) preoperatively to 8.4 (1-40) postoperatively. In total, 40 (66.7\%) subjects either quitting nicotine entirely or used less than they did before their surgery. This is similar to a prior study by Villebro et al. in which subjects who underwent a preoperative smoking cessation program smoked significantly less cigarettes postoperatively compared to those who did not (10 vs 13) [29]. However, this study only had a long-term tobacco-free survival of $8 \%$ at five years in those who were enrolled in a smoking cessation program. It is likely that only offering the subjects a smoking cessation program and not making it mandatory to quit prior to surgery led to the reduced long-term results.

Interestingly, a meta-analysis by Piasecki, found that recidivism rates at six months ranged from $69.5 \%$ to 88.2\% for all cessation methods [20]. Based on the data from the current study, it would appear that elective orthopedic surgery is an opportune moment to achieve nicotine cessation with recidivism superior to all other methods. Patients are usually receptive to the surgeon educating them on the risks of ongoing tobacco use during the perioperative period. They are also invested in their outcomes and desire to decrease perioperative risks. Therefore, most patients will comply with smoking cessation before surgery. This role of self-preservation is further supported by Shi and Warner. Their study found surgery to be the only independent predictor of successful tobacco cessation compared to other variables [22]. It is possible that combining mandatory preoperative smoking cessation prior to elective orthopedic surgery with a structured counseling or pharmacological program may increase the likelihood that patients will remain nicotine-free. However, this needs further investigation. 
predictor of nicotine use relapse in subjects undergoing elective hip surgery. This was compared to age, sex, BMI, and number of years of prior nicotine use. To the best of our knowledge, no other study in the orthopedic literature has attempted to identify risk factors for relapse. It is not surprising, however, that the more nicotine subjects use, the more likely they are to return to nicotine use postoperatively as quantity may be a surrogate for nicotine addiction [30]. This is compared to the duration of prior use where a subject may only use nicotine occasionally ("social smoker") despite using nicotine for decades.

There are limitations to this study. The study was retrospective possibly leading to selection bias. All surgeries were performed by a single fellowship-trained orthopedic surgeon with extensive experience in hip preservation surgery and total hip arthroplasty. Thus, the results of this investigation may not be extrapolated to all patient and surgeon populations. Additionally, postoperative nicotine use was based on self-reporting without confirmatory testing. This may have led to underreporting the number of patients who resumed tobacco use following their surgical procedure.

\section{Conclusions}

In conclusion, mandatory preoperative nicotine cessation prior to elective hip preservation surgery or total hip arthroplasty demonstrates a $46.7 \%$ nicotine-free survivorship at final follow-up with the number of preoperative cigarettes per day found to be the only independent predictor of nicotine use relapse. In addition, in the subjects who relapsed, the mean number of cigarettes per day significantly decreased compared to preoperatively. Future work should be done to explore the implementation of more guided cessation methods by healthcare professionals to ease the process for patients as many reported difficulties in quitting.

\section{Appendices}

\section{Patient survey}

1. Email Address

2. Name

3. Are you currently using tobacco products? If yes, how long after surgery did you resume?

4. Are you currently using nicotine vaporizers, electronic cigarettes, or other nicotine products? If yes, how frequently?

5. Did you use any smoking cessation methods to quit prior to surgery? (Prescription Medication, Nicotine Gum, Nicotine Patches, Vaporizer, Other)

6. If a smoker, how many years did you smoke prior to surgery? How many cigarettes per day?

7. Have you tried to quit using tobacco products before? If yes, how many times?

8. Were there other nicotine users in the household at the time when you quit or currently?

9. Would you recommend surgeons require patients to quit nicotine use prior to elective surgical procedures?

\section{Additional Information \\ Disclosures}

Human subjects: Consent was obtained by all participants in this study. Mount Carmel Institutional Review Board issued approval 180913-3. Animal subjects: All authors have confirmed that this study did not involve animal subjects or tissue. Conflicts of interest: In compliance with the ICMJE uniform disclosure form, all authors declare the following: Payment/services info: All authors have declared that no financial support was received from any organization for the submitted work. Financial relationships: All authors have declared that they have no financial relationships at present or within the previous three years with any organizations that might have an interest in the submitted work. Other relationships: All authors have declared that there are no other relationships or activities that could appear to have influenced the submitted work.

\section{References}

1. Jamal A, King BA, Neff LJ, Whitmill J, Babb SD, Graffunder CM: Current cigarette smoking among adults United States, 2005-2015. MMWR Morb Mortal Wkly Rep. 2016, 65:1205-1211. 10.15585/mmwr.mm6702a1

2. Smoking and tobacco use: fast facts. (2019). Accessed: February 6, 2019: https://www.cdc.gov/tobacco/data_statistics/fact_sheets/index.htm. 
3. A report of the surgeon general: how tobacco smoke causes disease . (2020). Accessed: December 11, 2020: https://www.cdc.gov/tobacco/data_statistics/sgr/2010/consumer_booklet/pdfs/consumer.pdf.

4. Jha P, Ramasundarahettige C, Landsman V, et al.: 21st-century hazards of smoking and benefits of cessation in the United States. N Engl J Med. 2013, 368:341-350. 10.1056/nejmsa1211128

5. National Center for Chronic Disease Prevention and Health Promotion (US) Office on Smoking and Health: The Health Consequences of Smoking-50 Years of Progress: A Report of the Surgeon General . Centers for Disease Control and Prevention, Atlanta; 2014.

6. Christiano AV, Pean CA, Konda SR, Egol KA: Predictors of patient reported pain after lower extremity nonunion surgery: the nicotine effect. Iowa Orthop J. 2016, 36:53-58.

7. Gronkjaer M, Eliasen M, Skov-Ettrup LS, et al.: Preoperative smoking status and postoperative complications: a systematic review and meta-analysis. Ann Surg. 2014, 259:52-71. 10.1097/SLA.0b013e3182911913

8. Ma L, Sham MH, Zheng LW, Cheung LK: Influence of low-dose nicotine on bone healing. J Trauma. 2011, 70:117-121. 10.1097/TA.0b013e3181e80dab

9. Møller AM, Villebro N, Pedersen T, Tønnesen H: Effect of preoperative smoking intervention on postoperative complications: a randomised clinical trial. Lancet. 2002, 359:114-117. 10.1016/S01406736(02)07369-5

10. Møller AM, Pedersen T, Villebro N, Munksgaard A: Effect of smoking on early complications after elective orthopaedic surgery. J Bone Joint Surg Br. 2003, 85:178-181. 10.1302/0301-620X.85B2.13717

11. Sloan A, Hussain I, Magsood M, Eremin O, El-Sheemy M: The effects of smoking on fracture healing . Surgeon. 2010, 8:111-116. 10.1016/j.surge.2009.10.014

12. Alverdy JC, Prachand V: Smoking and postoperative surgical site infection: where there's smoke, there's fire . JAMA Surg. 2017, 152:484. 10.1001/jamasurg.2016.5706

13. Duchman KR, Gao Y, Pugely AJ, Martin CT, Noiseux NO, Callaghan JJ: The effect of smoking on short-term complications following total hip and knee arthroplasty. J Bone Joint Surg Am. 2015, 97:1049-1058. 10.2106/JBJS.N.01016

14. Castillo RC, Bosse MJ, MacKenzie EJ, Patterson BM, LEAP Study Group: Impact of smoking on fracture healing and risk of complications in limb-threatening open tibia fractures. J Orthop Trauma. 2005, 19:151157.

15. Mills E, Eyawo O, Lockhart I, Kelly S, Wu P, Ebbert JO: Smoking cessation reduces postoperative complications: a systematic review and meta-analysis. Am J Med. 2011, 124:144-154. 10.1016/j.amjmed.2010.09.013

16. Song F, Brown TJ, Blyth A, Maskrey V, McNamara I, Donell S: Identifying and recruiting smokers for preoperative smoking cessation-a systematic review of methods reported in published studies. Syst Rev. 2015, 4:157.

17. Thomsen T, Tønnesen H, Møller AM: Effect of preoperative smoking cessation interventions on postoperative complications and smoking cessation. Br J Surg. 2009, 96:451-461. 10.1002/bjs.6591

18. Turan A, Koyuncu O, Egan C, You J, Ruetzler K, Sessler DI, Cywinski JB: Effect of various durations of smoking cessation on postoperative outcomes: a retrospective cohort analysis. Eur J Anaesthesiol. 2018, 35:256-265. 10.1097/EJA.0000000000000701

19. Warner MA, Offord KP, Warner ME, Lennon RL, Conover MA, Jansson-Schumacher U: Role of preoperative smoking cessation and other factors in postoperative pulmonary complications: a blinded prospective study of coronary artery bypass patients. Mayo Clin Proc. 1989, 64:609-616. 10.1016/S0025-6196(12)65337-3

20. Piasecki TM: Relapse to smoking. Clin Psychol Rev. 2006, 26:196-215. 10.1016/j.cpr.2005.11.007

21. Ucar EY, Araz O, Yilmaz N, Akgun M, Meral M, Kaynar H, Saglam L: Effectiveness of pharmacologic therapies on smoking cessation success: three years results of a smoking cessation clinic. Multidiscip Respir Med. 2014, 9:9. 10.1186/2049-6958-9-9

22. Shi Y, Warner DO: Surgery as a teachable moment for smoking cessation . Anesthesiology. 2010, 112:102107. 10.1097/ALN.0b013e3181c61cf9

23. Smith DH, McTague MF, Weaver MJ, Smith JT: Durability of smoking cessation for elective lower extremity orthopaedic surgery. J Am Acad Orthop Surg. 2019, 27:613-620. 10.1177/2473011419S00399

24. Taylor H, Karahalios A, Bramley D: Long-term effectiveness of the preoperative smoking cessation programme at Western Health. ANZ J Surg. 2017, 87:677-681. 10.1111/ans.14113

25. Carlson BB, Burton DC, Jackson RS, Robinson S: Recidivism rates after smoking cessation before spinal fusion. Orthopedics. 2016, 39:318-322. 10.3928/01477447-20160301-03

26. West R: Tobacco smoking: health impact, prevalence, correlates and interventions. Psychol Health. 2017, 32:1018-1036. 10.1080/08870446.2017.1325890

27. 2008 PHS Guideline Update Panel, Liaisons, and Staff: Treating tobacco use and dependence: 2008 update U.S. Public Health Service Clinical Practice Guideline executive summary. Respir Care. 2008, 53:1217-1222.

28. Hart A, Rainer WG, Taunton MJ, Mabry TM, Berry DJ, Abdel MP: Smoking cessation before and after total joint arthroplasty: an uphill battle. J Arthroplasty. 2019, 34:S140-S143. 10.1016/j.arth.2019.01.073

29. Villebro NM, Pedersen T, Møller AM, Tønnesen H: Long-term effects of a preoperative smoking cessation programme. Clin Respir J. 2008, 2:175-182. 10.1111/j.1752-699X.2008.00058.x

30. McNeill A, Driezen P, Hitchman SC, Cummings KM, Fong GT, Borland R: Indicators of cigarette smoking dependence and relapse in former smokers who vape compared to those who do not: findings from the 2016 International Tobacco Control Four Country Smoking and Vaping Survey. Addiction. 2019, 114:49-60. 10.1111/add.14722 